\title{
'Pre-feeding' embryos of antarctic and temperate echinoderms use dissolved organic material for growth and metabolic needs
}

\author{
Fraser M. Shilling ${ }^{1, *}$, Isidro Bosch ${ }^{2}$ \\ ${ }^{1}$ Department of Biological Sciences, University of Southern California, Los Angeles, California 90089, USA \\ ${ }^{2}$ Department of Biology, State University of New York, Geneseo, New York 14454, USA
}

\begin{abstract}
The energy reserves of eggs of marine invertebrates have been assumed to supply the metabolic needs of development until feeding on particles commences. This view is challenged by recent laboratory studies which show that marine invertebrate embryos of some nonarthropodan phyla are able to transport and use dissolved organic material (DOM, e.g. amino acids and fatty acids) in seawater as a source of material (energy) for metabolic needs and growth. Here we present results of experiments conducted in situ (in Antarctica and N. Pacific) and in the laboratory, which show that embryos could, in some cases, meet the metabolic costs of embryonic development and increase in organic weight (biomass) prior to being able to feed on particles. Increases in biomass of embryos of temperate species correlated with the timing of spring phytoplankton blooms. In contrast, the biomass of embryos (of temperate species) reared during periods of low primary productivity decreased, or remained constant. Phytoplankters exude DOM into seawater and these exudates are shown here to enhance embryonic growth. In most cases, there was no net use of endogenous reserves during prefeeding development; growth and energy needs were apparently met through consumption of DOM in seawater. We suggest that DOM is an important food source for embryos of soft-bodied marine invertebrates in polar and temperate oceans.
\end{abstract}

KEY WORDS: Embryogenesis - Antarctica - Dissolved organic material · Growth $\cdot$ Metabolism

\section{INTRODUCTION}

It has been known for 4 decades that sea urchin embryos have the capacity to transport organic compounds from seawater (e.g. amino acids: Hultin 1952, Mitchison \& Cummins 1966, Epel 1972). More recent work has shown that this process can take place at concentrations occurring naturally in seawater (Manahan et al. 1983). Embryos from 3 marine invertebrate phyla (Echinodermata, Echiura, and Mollusca) have exhibited net transport of dissolved organic material (DOM) from seawater (review: Manahan 1990), and it is likely that embryos of other nonarthropodan phyla have a similar capacity. Several components of DOM (e.g.

\footnotetext{
- Present address: Vollum Institute for Advanced Biomedical Research, Oregon Health Sciences University, 3181 SW Sam Jackson Park Rd., Portland, Oregon 97201, USA.
}

amino acids, fatty acids, and monosaccharides) are a source of anabolic and catabolic substrates for developing (Manahan 1990) and adult (Stephens \& Schinske 1961, Flood et al. 1992) stages of most marine invertebrates. However, the assumption is still made that embryos of most non-mammalian, externally developing animals rely solely on endogenous energy reserves ('yolk') to supply their metabolic needs until feeding on exogenous particulate matter begins (Davidson 1986. p. 162, Gurdon 1992, p. 190). This assumption is probably partly based on studies of the growth and metabolism of developing stages of sea urchins and molluscs, in which embryonic stages cultured under conditions where DOM was at low concentrations were shown to deplete their carbohydrate and lipid reserves (Mohri 1964, Hino \& Yasumasu 1979, Mann \& Gallager 1985).

DOM occurs at roughly 10 times the concentration of particulate organic material (POM) in the world's oceans (Parsons 1975, Williams 1975). Oceanic concen- 
trations of these organic compounds vary seasonally and geographically (Carlucci et al. 1984, Henrichs \& Williams 1985) depending at least in part on levels of primary production. There have been several recent investigations of the contribution of DOM in natural seawater to the metabolic costs of marine invertebrate embryos and larvae (Jaeckle \& Manahan 1989a, b, Manahan et al. 1989, Shilling \& Manahan 1990). It was demonstrated that, in laboratory cultures, ambient concentrations of DOM could supply up to $100 \%$ of the energy needs of early development (Shilling \& Manahan 1990). However, the actual contribution of DOM to development in the plankton is still unknown. Field concentrations of DOM can only be approximated in laboratory cultures. Moreover, the levels of both POM and DOM in the water column show seasonal variations related to primary productivity, but there have been no attempts to determine how the contribution of DOM to early development is influenced by this seasonality.

To address the importance of total DOM to the growth of developing marine invertebrates, embryos of echinoderm species from Antarctica and the West Coast of the U.S. were raised in the water columns of their respective environments, using an in situ culturing device (Olson 1985). This device has been used previously for the long-term culturing (several months) of echinoderm larvae in antarctic and tropical waters (Olson 1985, Olson et al. 1987). In the present study, 2 species from the antarctic echinoderm family Odontasteridae were chosen to represent 2 of the life-history strategies employed by species in Antarctica: Odontaster validus has small eggs $(180 \mu \mathrm{m})$ that develop into obligately planktotrophic larvae, Acodontaster hodgsoni has large $(550 \mu \mathrm{m})$ yolk-laden eggs and larvae that can develop to metamorphosis without feeding on particles. Nonfeeding embryos of these asteroids were cultured beneath the sea ice of McMurdo Sound, Antarctica, in early spring, when naturally spawned embryos were present (Pearse et al. 1991), but prior to the seasonal phytoplankton bloom (Bunt 1965). Embryos of several temperate species with planktotrophic larval development were also cultured in situ and in the laboratory using natural seawater. Experiments were carried out during different months of the year, to measure both the contribution of DOM to embryonic growth and the seasonal nature of this phenomenon. The species used were the sea star Asterina miniata, the sand dollar Dendraster excentricus, and the sea urchins Lytechinus pictus, Strongylocentrotus franciscanus, and Strongylocentrotus purpuratus. In addition, DOM concentrations were experimentally controlled in laboratory cultures to determine their effect on embryonic growth of the sea urchin S. purpuratus.

\section{MATERIALS AND METHODS}

Culturing in Antarctica. Adult Odontaster validus and Acodontaster hodgsoni were induced to spawn by intracoelomic injection of 1-methyladenine (Sigma Co.), and the eggs were collected for culturing from several females. Eggs were fertilized and the embryos cultured in filtered seawater $(0.2 \mu \mathrm{m}$ pore size) in Nalgene containers (volume $200 \mathrm{l}$ ) immersed in running seawater (temperature $=-1.3^{\circ} \mathrm{C}$ ). The culture was stirred vertically by a plastic paddle driven by an electric motor. The culture seawater was replaced every $5 \mathrm{~d}$ with newly filtered seawater. The temperature in the water column of McMurdo Sound is constant at this time of year, at $-1.9^{\circ} \mathrm{C}$ (Littlepage 1965) and the Sound is covered by 'sea ice'.

Embryos of Odontaster validus and Acodontaster hodgsoni were transferred from the stirred laboratory cultures at 'time zero' (blastula and gastrula stage) to the in situ culture chambers (Olson 1985). The chambers were sealed at both ends with $44 \mu \mathrm{m}$ (pore size) nylon mesh and mounted in a plexiglass culture system designed according to Olson (1985) and Olson et al. (1987). Ambient seawater was pumped through the chambers using a submersible pump, also mounted on the plexiglass. The intake for the pump was covered with $44 \mu \mathrm{m}$ mesh to reduce the amount of large particulate material entering the chambers (e.g. other animals and detritus). The whole apparatus was suspended beneath the sea ice, either at the surface (just beneath the sea ice), 'mid-depth' $(-7 \mathrm{~m})$ in the water column, or just above the bottom (benthos, $-20 \mathrm{~m}$ ), in McMurdo Sound, Antarctica. Ash-free dry organic weight (biomass) per embryo was determined (as described in Shilling \& Manahan 1990) at time zero, and when the embryos in the chambers were sampled. Briefly, a known number of embryos was rapidly washed 2 or 3 times in a volume excess $(\sim 30$-fold $)$ of $3.4 \%$ ammonium formate solution (iso-osmotic with seawater) to dilute out sea salts. The embryos were dried in aluminium weigh boats at $80^{\circ} \mathrm{C}$ for at least $1 \mathrm{wk}$, weighed, then ashed at $450^{\circ} \mathrm{C}$ for $5 \mathrm{~h}$ and weighed again. The difference between the ash weight and dry weight is the ash-free dry organic weight, or biomass, and was expressed per embryo. A total of 5 independent samples were taken per culturing chamber ( 3 chambers per culturing device). Biomass represents the organic mass that is theoretically available for consumption by metabolic machinery, either for anabolic or catabolic processes.

Culturing in California. The following species of temperate planktotrophic echinoderms were raised in situ: Strongylocentrotus purpuratus, S. franciscanus, Lytechinus pictus, Dendraster excentricus, and Asterina miniata. Culturing was conducted in 1990 and 
1991. Fertilized eggs were placed into in situ culturing devices similar to those used in Antarctica. One modification to the apparatus used in California was the addition of 300 and $80 \mu \mathrm{m}$ (pore size) meshes over the pump intake, which acted as 'pre-filters' for the $44 \mu \mathrm{m}$ mesh already present. Particulate material trapped on the intake mesh was periodically cleared. The devices were suspended approximately 1.5 to $3 \mathrm{~m}$ feet below the surface from the dock at the Catalina Marine Science Center, Santa Catalina Island, California. The dock is surrounded by a marine plant and animal reserve, with 2 nearby kelp forests. The temperature in this area ranges seasonally between 12 and $20^{\circ} \mathrm{C}$ ( Zimmerman \& Kremer 1984), depending on time of year. Biomasses of eggs and gastrula-stage embryos were measured as for the Antarctic species. Embryos were also cultured in the laboratory in seawater that had been freshly filtered $(0.2 \mu \mathrm{m}$ pore size $)$, in 20,50 , and $200 \mathrm{l}$ vessels, at temperatures ranging between 13 and $20^{\circ} \mathrm{C}$, corresponding to the ambient seawater temperature at the same time of year.

The effect of DOM concentrations on changes in biomass of pre-feeding stages was tested directly by culturing the embryos of Strongylocentrotus purpuratus in the presence of a phytoplankter (the diatom Thalassiosira pseudonana). Sibling embryos of $S$. purpuratus were raised in either: (1) filtered natural seawater (NSW, $0.2 \mu \mathrm{m}$ pore size), (2) artificial seawater (ASW, MBL formula), or (3) ASW to which $T$. pseudonana had been added. The diatom species was cultured in $f / 2$ medium (Guillard \& Ryther 1962). The algae were washed with seawater (to remove the $f / 2$ medium) prior to use. Concentrations of algae in experimental containers were as follows: culture $3,5.0 \times 10^{5}$ cells $\mathrm{ml}^{-1}$; culture $4,5.7 \times 10^{5}$ cells ml${ }^{-1}$; culture $5,8.7 \times 10^{5}$ cells ml ${ }^{-1}$. Biomass was measured as above.

All statistical significances were determined using analysis of variance (ANOVA), to compare measured biomasses among different stages (Zar 1984).

\section{RESULTS}

\section{Changes in biomass of antarctic embryos in situ}

Embryos of Odontaster validus, over certain periods (e.g. Day 6 to Day 15, Fig. 1a), increased significantly in biomass (ANOVA, $p<0.05$ ). There were no significant decreases in biomass $(p>0.20)$ during the entire 3 wk culturing period. The stages of development represented in this experiment [unhatched blastula (Day 6) to the late gastrula stage (Day 29) just prior to fusion of gut with blastocoelic wall] are all incapable of feeding on particles. With no consumption of exogenous nutrients, the metabolic costs of development would result in a loss of biomass (indicated by arrows,
Fig. 1a). Embryos on only 1 sampling day (Day 21) showed a biomass loss similar to the expected values calculated from metabolic rates (rate $=3 \mathrm{pmol} \mathrm{O}_{2}$ embryo $^{-1} \mathrm{~h}^{-1}$, from Manahan et al. 1990). The biomass equivalent to a given rate of oxygen consumption was calculated using energy equivalents given in Gnaiger (1983). The oxyenthalpic equivalent used was $484 \mathrm{~kJ}$ $\mathrm{mol}^{-1} \mathrm{O}_{2}$, and the enthalpy of combustion for biomass $27.0 \mathrm{~kJ} \mathrm{~g}^{-1}$ (Gnaiger 1983).

In contrast to Odontaster validus, embryos of Acodontaster hodgsoni did not change in biomass when cultured in situ ( $p>0.05$, Fig. 1b). The stages represented here are morula to late gastrula; development in situ progressed normally, at rates comparable to those in culture maintained under controlled laboratory conditions.

\section{Seasonal biomass changes of temperate embryos in natural seawater}

In similar experiments carried out in situ off the coast of Southern California, pre-feeding embryos of several echinoderm species increased significantly in biomass ( $p<0.05$, Fig. 1c), but only in the spring and early summer. The biomass of embryos reared between late summer and winter either did not change $(p>0.10)$ or decreased $(p<0.05)$, relative to the egg. In the region where these measurements were conducted, phytoplankton blooms that occur in the spring and summer (Eppley \& Holm-Hansen 1986) could provide seasonal enhancement of the DOM available for the growth of embryos and larvae.

To further test this idea, changes in biomass of embryos cultured either in NSW or in situ were compared to the time of year in which they were raised. Change in biomass was expressed as a percentage: [biomass of the egg / (biomass of the embryo - biomass of the egg)] $\times 100 \%$. Growth (increase in biomass) of embryos of Strongylocentrotus purpuratus occurred primarily in the spring ( 8 of 9 increases, Fig. 2a). In contrast, embryos cultured in the winter usually decreased or did not change in biomass. Similar results were obtained for 41 cultures of embryos of 5 temperate echinoderm species (Fig. 2b). Between March and August, in 11 of 18 cultures, embryos gained biomass, compared to decreases in 2 cultures; embryos in the remaining 5 cultures did not change in biomass.

\section{Use of biomass to meet metabolic costs: Strongylocentrotus purpuratus}

The measured changes in biomass of developing embryos of Strongylocentrotus purpuratus were compared with the decreases that would be expected due to the use of endogenous reserves to meet metabolic 
needs (Table 1). The rate of oxygen consumption for embryos of $S$. purpuratus is $8 \mathrm{pmol} \mathrm{O}_{2}$ embryo $^{-1} \mathrm{~h}^{-1}$ (Shilling \& Manahan 1990); the expected decrease in biomass was calculated as for embryos of Odontaster validus. In only 5 of 19 cultures of $S$. purpuratus were the changes in biomass sufficient to meet metabolic costs (Table 1$)_{i}$ these cultures were conducted in the
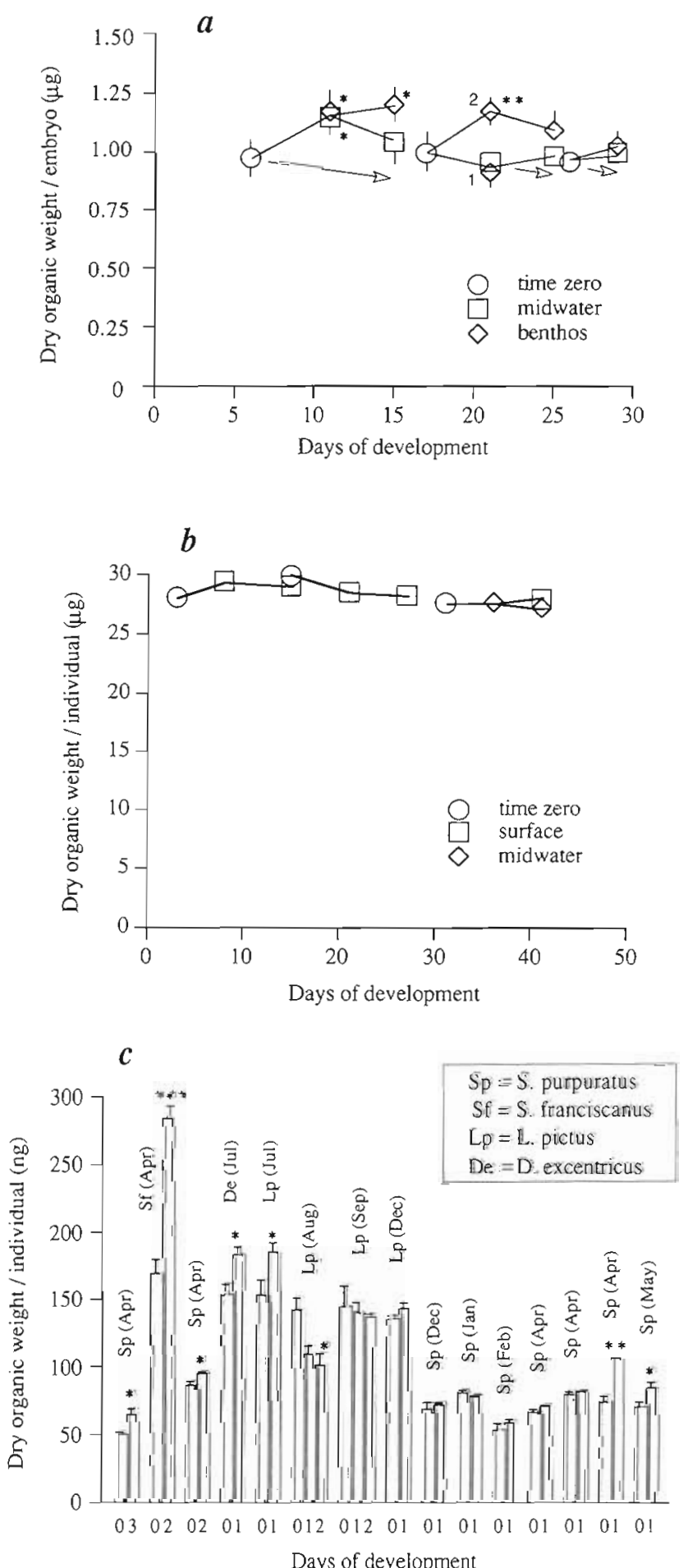

winter. In the remaining cultures, primarily in the spring, embryos did not show a net depletion of biomass needed to meet metabolic demand, suggesting that the source of organic material for this cost was exogenous.

\section{Relationship between biomass changes of embryos and presence of phytoplankton}

A variety of indicators of water column productivity, taken from published studies, show the seasonal nature of this process (Fig. 2c). Typically, in the Southern California Bight, increases in primary production in the water column begin between February and May (Fig. 2c). This correlates well with the time when growth of the temperate echinoderm embryos was observed (Fig. 2a, b). The period of reduced productivity is typically between October and February, which is the time when embryos in the majority of cultures decreased or did not change in organic weight.

In order to examine more closely the relationship between the presence of phytoplankton and the changes in embryonic biomass, the embryos were cultured in the presence, or absence, of the alga Thalassiosira pseudonana. Embryos raised in NSW, or ASW with added algae, were always significantly greater in biomass ( $p<0.05$, comparison not shown) than sibling embryos raised in ASW alone (Fig. 3). In 4 of the 5 cultures, the embryos in NSW, or ASW with added algae, were also greater in biomass $(p<0.05)$ than the egg (indicated by " and $\cdots$, Fig. 3).

Fig. 1. Changes in ash-free dry organic weight (biomass) of pre-feeding embryos of 2 Antarctic asteroids, (a) Odontaster validus and (b) Acodontaster hodgsoni, and (c) 4 temperate echinoids and a temperate asteroid, Asterina miniata, Dendraster excentricus, Lytechinus pictus, Strongylocentrotus purpuratus, and $S$. franciscanus, cultured in situ in the water column. Significance of changes in biomass, between embryos removed from the in situ device and eggs at time zero, was determined by analysis of variance. Significances: - $p<0.05 ; \cdots p<0.01$; and $\cdots p<0.001$. (a) Biomass per embryo for $O$. validus. The theoretical loss in biomass (indicated by arrows) was calculated as in Table 1 . Error bars represent $95 \%$ confidence intervals; where no bars are shown, the intervals are within the graphical representation of the point. The number of chambers is indicated beside the data points for the sampling day on which embryos from one of the benthic chambers were significantly different in biomass from embryos in the other 2. (b) Biomass changes per embryo for $A$. hodgsoni; the error bars are within the graphical representation of the point. Three chambers were sampled per data point, except time zero. (c) Biomasses of eggs (Day 0) and gastrula stage embryos ( 1 to $2.5 \mathrm{~d}$ old $)$ of the temperate echinoderms. Error bars represent $1 \mathrm{SE}$ of the mean 


\section{DISCUSSION}

Embryos of antarctic and temperate echinoderms, with planktotrophic development, gained biomass when cultured in their respective oceanic habitats. Because these embryos (zygote to gastrula) cannot feed on particles, the growth can only be attributed to the absorption of nonparticulate (i.e. dissolved) organic material. The correlation of growth of embryos with
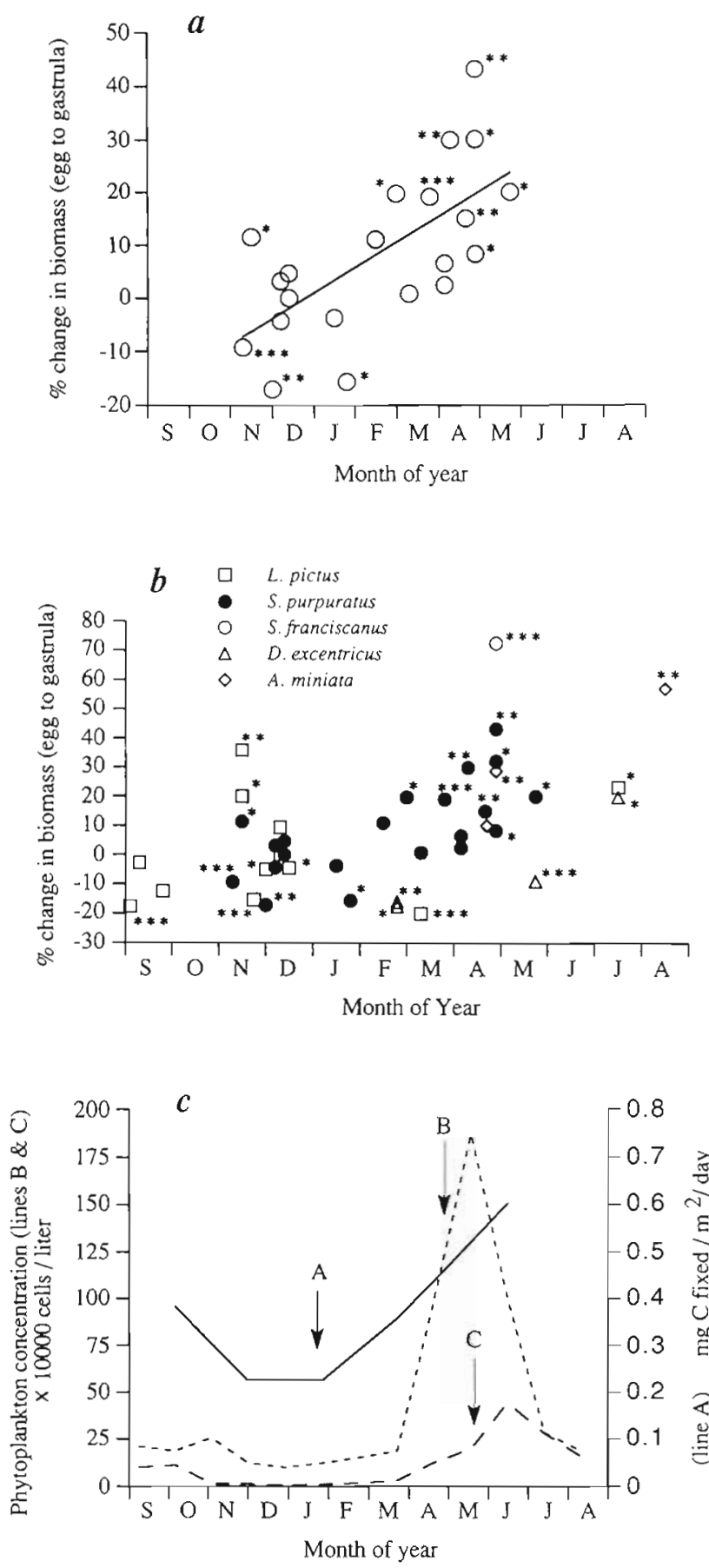

seasonal primary productivity in temperate seawater suggests that the presence of phytoplankton is necessary for growth of the pre-feeding developing stages of the temperate echinoderms. However, survival of the embryos until the larval stage no doubt can still occur in nutrient-poor seawater. The one species with large, yolk-laden embryos and larvae (antarctic: Acodontaster hodgsoni) had no significant change in organic biomass during embryogenesis. Factors that affect the availability and quality of DOM (e.g. changes in oceanic productivity) and the ability of the developing stages to consume it (e.g. physiological state) may have an impact on the viability of these stages in the water column.

\section{Use of endogenous reserves in meeting metabolic cost during embryogenesis}

Yolk has traditionally been regarded as the primary source of energy for embryonic development of marine invertebrates (e.g. Davidson 1986, Scott et al. 1990). Early studies of the energetics of molluscan and echinoderm embryos involved measurements of depletion of endogenous energy reserves (e.g. carbohydrate and lipid) under conditions where exogenous DOM was at low concentrations, or not available (Hayes 1938, Mohri 1964, Hino \& Yasumasu 1979, Mann \& Gallager 1985). In our study, the lack of significant biomass changes in embryos of Acodontaster hodgsoni suggests that this species may follow a similar pattern of dependence on internal reserves. However, it is possible that over the time course of culturing in this study any change may have been unmeasurable using the

Fig. 2. Changes in biomass of embryos of temperate echinoderms [Lytechinus pictus, Strongylocentrotus purpuratus, $S$. franciscanus, Dendraster excentricus (echinoids), and Asterina miniata (asteroid)] cultured in natural seawater. Significant changes in biomass from egg to gastrula are indicated as for Fig. 1. (a) Percent change in biomass from egg to gastrula stage embryos of $S$. purpuratus, compared to time of year when culturing was conducted. Percent change was calculated as follows: [biomass of the egg/(biomass of the embryo - biomass of the egg)] $\times 100 \%$. Embryos were cultured either in situ or in filtered natural seawater between 1986 and 1991 . The sloped line indicates the results of a linear regression analysis of percent growth relative to time of year. (b) Percent change in biomass from egg to gastrula stage for all 5 species of temperate echinoderms (listed above). (c) Primary productivity in the water column of the Southern California Bight. Rates of carbon fixation (line A) were calculated (Smith \& Eppley 1982) from data given in Allen (1941). Lines B and C represent the concentrations of phytoplankton cells (dinoflagellates) averaged over the years 1920 to 1940 (Allen 1941) in the water columns off Scripps Institute of Oceanography (line B) and Port Hueneme (line C) 
Table 1. Strongylocentrotus purpuratus. Changes in dry organic weight (aerobically catabolized biomass) compared to the expected decrease due to metabolic demand for egg to gastrula stage. Culturing conducted in situ and in filtered $(0.2 \mu \mathrm{m}$ pore size) natural seawater (data from Fig. 2a). The expected decrease in biomass was calculated by converting the rate of oxygen consumption for embryos (8 pmol $\mathrm{O}_{2}$ embryo $^{-1} \mathrm{~h}^{-1}$; Shilling \& Manahan 1990) to organic mass, using average enthalpic equivalents for the combustion of protein, lipid, and carbohydrate $\left(484 \mathrm{~kJ} \mathrm{~mol}^{-1} \mathrm{O}_{2}, 27.0 \mathrm{~kJ} \mathrm{~g}^{-1}\right.$ biomass; Gnaiger 1983). MR: metabolic rate; $>\mathrm{MR}$ : measured biomass was greater than expected biomass ${ }_{i}=\mathrm{MR}$ : the decrease in biomass was equal to the expected depletion needed to meet metabolic requirements

\begin{tabular}{|c|c|c|c|c|}
\hline \multirow[t]{2}{*}{ Month } & \multicolumn{2}{|c|}{ Mean biomass $(\mathrm{ng})( \pm 95 \% \mathrm{CI})$} & \multirow{2}{*}{$\begin{array}{l}\text { Expected biomass (ng) } \\
\text { at gastrula stage }\end{array}$} & \multirow[t]{2}{*}{$>/=\mathrm{MR}$} \\
\hline & Egg & Gastrula & & \\
\hline Nov & $69.6(0.33)$ & $63.2(2.13)$ & 66.2 & $=\mathrm{MR}$ \\
\hline Nov & $106.2(6.31)$ & $122.8(10.9)$ & 99.2 & $>\mathrm{MR}$ \\
\hline Dec & $82.0(1.83)$ & $81.6(6.32)$ & 78.6 & $=M R$ \\
\hline Dec & $63.2(2.16)$ & $51.4(4.53)$ & 59.8 & $=\mathrm{MR}$ \\
\hline Dec & $68.5(10.8)$ & $71.7(3.87)$ & 65.1 & $>\mathrm{MR}$ \\
\hline Jan & $80.7 \quad(3.92)$ & $77.7(2.84)$ & 77.3 & $=\mathrm{MR}$ \\
\hline Jan & $59.8(4.99)$ & $50.5(2.53)$ & 49.1 & $=\mathrm{MR}$ \\
\hline Feb & $53.4(10.5)$ & $58.7(4.82)$ & 50.0 & $>\mathrm{MR}$ \\
\hline Mar & $60.9(6.40)$ & $73.9(3.70)$ & 50.2 & $>\mathrm{MR}$ \\
\hline Mar & $53.0(3.54)$ & $53.4(2.09)$ & 49.6 & $>\mathrm{MR}$ \\
\hline Mar & $73.7(0.77)$ & $87.8(4.80)$ & 63.0 & $>\mathrm{MR}$ \\
\hline Apr & $68.1(2.97)$ & $70.6(2.40)$ & 64.7 & $>\mathrm{MR}$ \\
\hline Арг & $79.2(4.51)$ & $81.1(1.76)$ & 75.8 & $>\mathrm{MR}$ \\
\hline Арг & $70.3(3.10)$ & $91.3(8.05)$ & 59.6 & $>\mathrm{MR}$ \\
\hline Apr & $68.5(2.64)$ & $78.8 \quad(3.67)$ & 65.1 & $>\mathrm{MR}$ \\
\hline Apr & $49.9(4.58)$ & $65.0(9.28)$ & 31.9 & $>\mathrm{MR}$ \\
\hline Apr & $73.7 \quad(9.42)$ & $105.5(0.45)$ & 70.4 & $>\mathrm{MR}$ \\
\hline Apr & $86.4(6.36)$ & $94.7(3.15)$ & 75.7 & $>\mathrm{MR}$ \\
\hline May & $70.0(8.07)$ & $85.6(8.91)$ & 66.6 & $>\mathrm{MR}$ \\
\hline
\end{tabular}

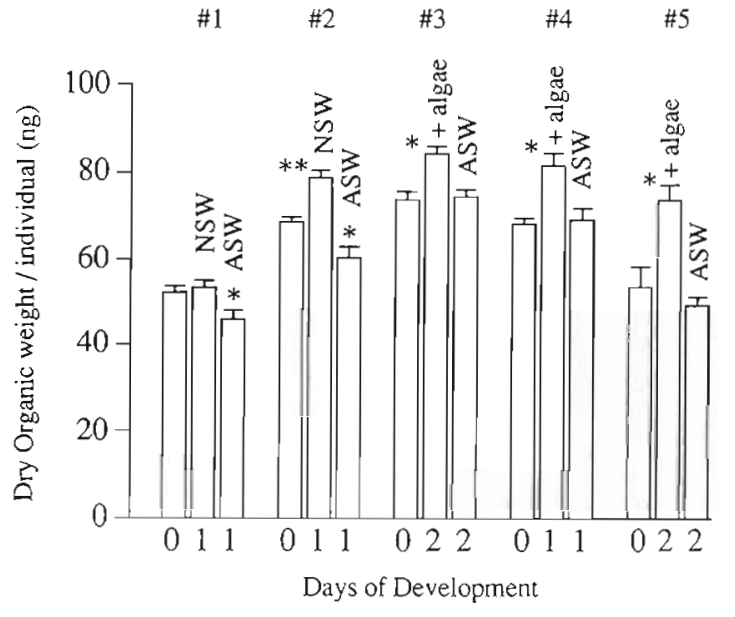

Fig. 3. Strongylocentrotus purpuratus. Effect of DOM on changes in biomass of pre-feeding embryos. Sibling embryos were cultured from eggs either in filtered $(0.2 \mu \mathrm{m}$ pore size) natural seawater, artificial seawater (ASW, MBL formula), or ASW to which the diatom Thalassiosira pseudonana had been added. Concentrations of algae in experimental containers are given in 'Materials and methods'. Significance of changes in biomass, between eggs and embryos was determined by analysis of variance: " $p<0.05 ; \cdots p<0.01$. Each bar represents the mean of 6 samples for biomass, error bar represents $1 \mathrm{SE}$ of the mean. Data from cultures \#1 and 2 have appeared previously (Shilling \& Manahan 1990) techniques we employed. In the other species used, all of which have planktotrophic development, increases in organic mass were observed. Recently, there has been evidence that yolk proteins do not decrease significantly in amount in early sea urchin embryos (Armant et al. 1986) and starving sea urchin larvae, but do decrease when the larvae are fed (Scott et al. 1990). Thus, the yolk proteins may be needed by the early larval stages under nutritional conditions when normal development can occur (i.e. where food is present), but are not the natural source of material and energy for pre-feeding stages. Our observation, that pre-feeding echinoderm embryos showed no net use of endogenous reserves to meet energy needs, but instead used exogenous DOM, raises the possibility that DOM may be the natural source of energy and material for marine invertebrate embryos developing in the plankton.

\section{Using DOM to meet metabolic needs}

The availability of DOM to marine organisms is, for the most part, unknown. Total DOM has been measured by several techniques (Menzel \& Vaccaro 1964, Sugimura \& Suzuki 1988) and the natural concentrations (as micromolar carbon) are the subject of considerable controversy (Ogawa \& Ogura 1992). 
Concentrations of individual components of this pool (monosaccharides: Mopper et al. 1980, amino acids: Manahan \& Stephens 1983) have also been determined. However, the actual mass of DOM that can be consumed by marine organisms in situ has not been measured. Corollaries of the amount of DOM that can be removed from seawater are (1) the gain in organic mass and (2) the use of DOM by the organism to meet metabolic needs, which are the quantities measured in the present study.

The results of the present study are consistent with previous work with laboratory-cultured embryos and larvae, Jaeckle \& Manahan (1989a, b) demonstrated that 'nonfeeding' embryos and larvae of the mollusc Haliotis rufescens transported components of DOM from seawater and used DOM to meet $55 \%$ of metabolic needs (as determined by oxygen consumption). Similarly, Shilling \& Manahan (1990) showed that prefeeding embryos of an echinoderm (Strongylocentrotus purpuratus) met $100 \%$ of metabolic cost using exogenous DOM. A study with the antarctic species Odontaster validus demonstrated that the early developing stages could theoretically meet $100 \%$ of metabolic needs by taking up dissolved free amino acids at concentrations (150 $\mathrm{nM}$ ) found in the water column of Antarctica (Shilling \& Manahan 1991). Embryos of $O$. validus also did not lose biomass from the egg to early bipinnaria stage when cultured in the laboratory at low densities in freshly filtered seawater (Shilling \& Manahan unpubl.). In the present study, pre-feeding embryos of antarctic and temperate echinoderms developing in situ often did not decrease in biomass, and in some instances gained in biomass. They must therefore be able to use DOM in seawater, at naturally occurring concentrations, to meet the metabolic costs of embryogenesis. Because later-developing stages increase in their ability to transport components of DOM to match increases in metabolic need (Manahan et al. 1989), it is likely that these later stages also benefit nutritionally from DOM in seawater.

\section{Seasonality in the contribution of DOM to embryonic nutrition}

Embryos of temperate echinoderms gained in biomass in spring and early summer, coincident with the spring phytoplankton bloom in temperate coastal waters. Even when biomass increases were not found, some fraction of metabolic cost was usually met by consumption of DOM. Concentrations of dissolved free amino acids in temperate seawaters range from 0 to several hundred nM (Manahan \& Stephens 1983, Carlucci et al. 1984, Henrichs \& Williams 1985, Jaeckle \& Manahan 1992). However, it is not currently known how concentrations of these and other dissolved organic compounds change seasonally, such as during the spring and summer when certain echinoderms spawn (e.g. Strongylocentrotus purpuratus and Lytechinus pictus). Phytoplankton exude dissolved organic compounds such as amino acids (Flynn 1990), fatty acids (Kattner \& Brockmann 1990), and carbohydrates (Myklestad \& Haug 1972). There may therefore be a relationship between the presence of phytoplankton (i.e. in a seasonal bloom) and the concentration of biologically available DOM (Kirchmann et al. 1991). The exudates from phytoplankters will serve as nutrients to bacteria, as well as any other heterotrophic organism capable of removing them from seawater. The coincidence between the spawning of temperate marine invertebrates and spring phytoplankton blooms (Barnes 1957, Starr et al. 1990) may serve to maximize the availability of both particulate and dissolved organic material to embryos and larvae.

Experimentally changing the concentration of DOM affected the changes in biomass of temperate embryos in a manner consistent with the observation that growth of the embryos in natural seawater correlates with seasonal phytoplankton blooms. When DOM concentration was maintained or augmented by using natural seawater, or adding algae to artificial seawater, embryos, unable to feed on particles, gained in biomass. Conversely, embryos cultured in artificial seawater lost biomass. It is assumed here that the addition of a phytoplankter resulted in an (unmeasured) increase in DOM concentration due to exudation from the algae. Jaeckle \& Manahan (1992) found that passage of seawater through the sand filter of an aquaculture facility reduced the dissolved free amino acid concentration, and that abalone larvae Haliotis rufescens used more of their endogenous energy reserves in this seawater than in seawater that had not been treated in this manner.

In Antarctica, monosaccharides and amino acids occur at lower concentrations ( 0 to $200 \mathrm{nM}$ ) during the austral winter and the beginning of spring (Manahan et al. 1990). This is also a time of year characterized by low levels of primary productivity (Rivkin 1991) and the spawning of echinoderms (Pearse et al. 1991). Although the concentrations of some components of DOM may be low (relative to temperate regions) in the austral spring, there is apparently sufficient material to allow embryos of Odontaster validus to meet energy needs and gain biomass.

\section{Use of components of DOM other than dissolved free amino acids}

It is unlikely that uptake of dissolved free amino acids (DFAA) alone from seawater could account for biomass gains of the embryos as these compounds con- 
stitute only $1 \%$ of the total DOM (Williams 1975). Previous calculations for Strongylocentrotus purpuratus showed that embryos could take up $2.1 \mathrm{ng}$ amino acid $\mathrm{d}^{-1}$ from a concentration of 500 nM DFAA (Shilling \& Manahan 1990). This rate of acquisition would be insufficient to meet many of the biomass gains actually measured for embryos of this species (Table 1). However, other possible sources of material exist, such as dissolved combined amino acids (DCAA). These are a large component of DOM which can support greater than $50 \%$ of the growth of marine bacteria (Coffin 1989) and which occur at micromolar concentrations in seawater (Keil \& Kirchmann 1991). To date, the contribution of components of the DOM such as DCAA (and other macromolecular compounds) to the growth and energy needs of developing stages of marine invertebrates has received little attention compared to the relatively minor component, DFAA.

Acknowledgements. We thank Drs John Pearse and Donal Manahan for valuable discussions about experimental design, and the scientific staff and support personnel at both McMurdo Station, Antarctica and the Catalina Marine Science Center, Santa Catalina Island, California. This research was supported by NSF Grant DPP 88-20130 to D. Manahan (University of Southern California) and NSF grant DPP 8818354 to J. Pearse (University of California, Santa Cruz).

\section{LITERATURE CITED}

Allen, W. E. (1941). Twenty years' statistical studies of marine plankton dinoflagellates of Southern California. Am. Midl. Nat. 26: 603-635

Armant, D. R., Carson, D. D., Decker, G. L., Welply, J. K., Lennarz, W. J. (1986). Characterization of yolk platelets isolated from developing embryos of Arbacia punctulata. Dev. Biol. 113: 342-355

Barnes, H. (1957). Processes of restoration and synchronization in marine ecology. The spring diatom increase and the 'spawning' of the common barnacle, Semibalanus balanoides (L.). Ann. Biol. 33: 67-85

Bunt, $J$. (1965). Primary productivity under sea ice in antarctic waters. 1 . Concentrations and photosynthetic activities of microalgae in the waters of McMurdo Sound, Antarctica Antarct. Res. Ser. 1: 27-31

Carlucci, A. F., Craven, D. B., Henrichs, S. M. (1984). Diel production and microheterotrophic utilization of dissolved free amino acids in waters off Southern California. Appl. environ. Microbiol. 48: 165-170

Coffin, R. B. (1989). Bacterial uptake of dissolved free and combined amino acids in estuarine waters. Limnol Oceanogr. 34(3): 531-542

Davidson, E. H. (1986). Gene activity in early development 3rd edn. Academic Press, Inc, New York

Epel, D. (1972). Activation of an $\mathrm{Na}^{+}$-dependent amino acid transport system upon fertilization of sea urchin eggs. Exp. Cell Res. 72: 74-89

Eppley, R. W., Holm-Hansen, O. (1986). Primary production in the Southern California Bight. In: Eppley, R. W. (ed.) Lecture notes on coastal and estuarine studies. 15. Plankton dynamics of the Southern California Bight. SpringerVerlag, New York, p. 176-215
Flood, P. R., Deibel, D., Morris, C. C. (1992). Filtration of colloidal melanin from sea water by planktonic tunicates. Nature 355: 630-632

Flynn, K. J. (1990). Composition of intracellular and extracellular pools of amino acids, and amino acid utilization of microalgae of different sizes. J. exp. mar. Biol. Ecol. 139: $151-166$

Gnaiger, E. (1983). Calculation of energetic and biochemical equivalents of respiratory oxygen consumption. In: Gnaiger, E., Forstner, H. (eds.) Polarographic oxygen sensors, Springer-Verlag, New York, p. 337-345

Guillard, R. R. L., Ryther, J. H. (1962). Studies of marine planktonic diatoms. I. Cyclotella nana Hustedt and Detonula confervacea (Cleve) Gran. Can. J. Microbiol. 8: 229-239

Gurdon, J. B. (1992). The generation of diversity and pattern in animal development. Cell 68: 185-199

Hayes, F. R. (1938). The relation of fat changes to the general chemical embryology of the sea urchin. Biol. Bull. 74: 267-277

Henrichs, S. M., Williams, P. M. (1985). Dissolved and particulate amino acids and carbohydrates in the sea surface microlayer. Mar. Chem. 17: 141-164

Hino, A., Yasumasu, I. (1979). Change in the glycogen content of sea urchin eggs during early development. Dev. Growth Differ. 21: 229-236

Hultin, $\mathrm{T}$ (1952). Incorporation of ${ }^{15} \mathrm{~N}$-labeled glycine and alanine into the proteins of developing sea urchin eggs. Exp. Cell Res. 3: 494-501

Jaeckle, W. B., Manahan, D. T (1989a). Growth and energy imbalance during the development of a lecithotrophic molluskan larva (Haliotis rufescens). Biol. Bull. 177: $237-246$

Jaeckle, W. B., Manahan, D. T. (1989b). Feeding by a 'nonfeeding' larva: uptake of dissolved amino acids from seawater by lecithotrophic larvae of the gastropod Haliotis rufescens. Mar. Biol. 103: 87-94

Jaeckle, W. B., Manahan, D. T. (1992). Experimental manipulations of the organic composition of seawater: implications for studies of energy budgets in marine invertebrate larvae. J. exp. mar. Biol. Ecol. 156: 273-284

Kattner, G., Brockmann, U. H. (1990). Particulate and dissolved fatty acids in an enclosure containing a unialgal Skeletonema costatum (Greve.) Cleve culture. J. exp. mar. Biol. Ecol. 141: 1-13

Keil, R. G., Kirchman, D. L. (1991). Dissolved combined amino acids in marine waters as determined by a vapor-phase hydrolysis method. Mar. Chem. 33: 243-259

Kirchmann, D. L., Suzuki, Y., Garside, C., Ducklow, H. W. (1991). High turnover rates of dissolved organic carbon during a spring phytoplankton bloom. Nature 352: $612-614$

Littlepage, J. L. (1965). Oceanographic investigations in McMurdo Sound, Antarctica. Antarct. Res. Ser. 5: 1-37

Manahan, D. T., Davis, J. P., Stephens, G. C. (1983). Bacteriafree sea urchin larvae: selective uptake of neutral amino acids from seawater. Science 220: 204-206

Manahan, D. T., Jaeckle, W. B., Nourizadeh, S. N. (1989). Ontogenic changes in the rates of amino acid transport by marine invertebrate larvae. Biol. Bull. 176: 161-168

Manahan, D. T. (1990). Adaptations by invertebrate larvae for nutrient acquisition from seawater. Am. Zool 30: 147-160

Manahan, D. T., Shilling, F. M., Welborn, J. R., Colwell, S. J. (1990). Dissolved organic material in seawater as a source of nutrition for invertebrate larvae from McMurdo Sound, Antarctica. Antarct. J. U.S. 25(5): 206-208

Manahan, D. T., Stephens, G. C. (1983). The use of high- 
performance liquid chromatography to measure dissolved organic compounds in bivalve aquaculture systems Aquaculture 32: 339-346

Mann, R., Gallager, S. M. (1985). Physiological and biochemical energetics of larvae of Teredo navalis $\mathrm{L}$. and Bankia gouldi (Bartsch) (Bivalvia: Teredinidae). J. exp. mar. Biol. Ecol. 85: 211-228

Menzel, D. W., Vaccaro, R. F. (1964). The measurements of dissolved and particulate carbon in seawater. Limnol Oceanogr. 9: 138-142

Mitchison, J. M., Cummins, J. E. (1966). The uptake of valine and cytidine by sea urchin embryos and its relation to the cell surface. J. Cell Sci. 1: 35-47

Mohri, H. (1964). Utilization of $\mathrm{C}^{14}$-labeled acetate and glycerol for lipid synthesis during the early development of sea urchin embryos. Biol. Bull. mar. biol. Lab., Woods Hole 126: $440-445$

Mopper, K., Ittekot, V., Dawson, R., Liebezeit, G. (1980). The monosaccharide spectra of natural waters. Mar. Chem. 10: $55-66$

Myklestad, S., Haug, A. (1972). Production of carbohydrates by the marine diatom Chaetocerous affinis var. willei (Gran) Hustedt. I. Effect of the concentration of nutrients in the culture medium. J. exp. mar. Biol. Ecol. 9: 125-136

Ogawa, H., Ogura, N. (1992). Comparison of two methods for measuring dissolved organic carbon in sea water. Nature 356: $696-698$

Olson, R. R. (1985). In situ culturing of larvae of the crown-ofthorns starfish Acanthaster planci. Mar. Ecol. Prog. Ser. 25: $207-210$

Olson, R. R., Bosch, I., Pearse, J. S. (1987). The hypothesis of antarctic larval starvation examined for the asteroid Odontaster validus. Limnol. Oceanogr. 32(3): 686 690

Parsons, T. (1975). Particulate organic carbon in the sea. In: Riley, J P., Skirrow, G. (eds.) Chemical oceanography, Vol. 2. Academic Press, London, p. 365-386

Pearse, J. S., McClintock, J. B., Bosch, I. (1991). Reproduction

This article was submitted to the editor of antarctic benthic marine invertebrates: tempos, modes, and timing. Am. Zool. 31(1): 65-80

Rivkin, R. R. (1991). Seasonal patterns of planktonic production in McMurdo Sound, Antarctica. Am. Zool. 31: 5-16

Scott, L. B., Leahy, P. L., Decker, G. L., Lennarz, W. J. (1990). Loss of yolk platelets and yolk glycoproteins during larval development of the sea urchin embryo. Dev. Biol. 137: 368-377

Shilling, F. M., Manahan, D. T (1990). Energetics of early development for the sea urchins Strongylocentrotus purpuratus and Lytechinus pictus and the crustacean Artemia sp. Mar. Biol. 106: 119-127

Shilling, F. M., Manahan, D. T. (1991). Nutrient transport capacities and metabolic rates scale differently between larvae of an Antarctic and a temperate echinoderm. Antarct J. U.S. 26(5): 158-160

Smith, P. E., Eppley, R. W. (1982). Primary production and the anchovy population in the Southern California Bight: comparison of time series. Limnol. Oceanogr. 27(1): 1-17

Starr, M., Himmelman, J. H., Theriault, J.-C. (1990). Direct coupling of marine invertebrate spawning with phytoplankton blooms. Science 247: 1071-1074

Stephens, G. C., Schinske, R. A. (1961). Uptake of amino acids by marine invertebrates. Limnol. Oceanogr. 6: 175-181

Sugimura, Y., Suzuki, Y. (1988). A high-temperature catalytic oxidation method for the determination of non-volatile dissolved organic carbon in seawater by direct injection of a liquid sample. Mar. Chem. 24: 105-131

Williams, P. J. leB. (1975). Biological and chemical aspects of dissolved organic material in seawater. In: Riley, J. P., Skirrow, G. (eds.) Chemical oceanography, Vol. 2. Academic Press, London, p. 301-364

Zar, J. H. (1984). Biostatistical analysis. Prentice-Hall, Inc., Englewood Cliffs, NJ

Zimmerman, R. C., Kremer, J. N. (1984). Episodic nutrient supply to a kelp forest ecosystem in Southern California. J. mar. Res. 42: 591-604

Manuscript first received: September 17, 1993

Revised version accepted: March 31, 1994 